\title{
Embracing Advanced Digital Services in the Charity and Voluntary Sector: A Response to Covid-19
}

Link to publication record in Manchester Research Explorer

\section{Citation for published version (APA):}

Raki, A., Chowdhury, I. N., Nieroda, M., \& Zolkiewski, J. (Accepted/In press). Embracing Advanced Digital Services in the Charity and Voluntary Sector: A Response to Covid-19. In Proceedings of Competitive Advantage in the Digital Economy CADE 2021: Sustainability, Resilience, and Trust and Privacy

\section{Published in:}

Proceedings of Competitive Advantage in the Digital Economy CADE 2021

\section{Citing this paper}

Please note that where the full-text provided on Manchester Research Explorer is the Author Accepted Manuscript or Proof version this may differ from the final Published version. If citing, it is advised that you check and use the publisher's definitive version.

\section{General rights}

Copyright and moral rights for the publications made accessible in the Research Explorer are retained by the authors and/or other copyright owners and it is a condition of accessing publications that users recognise and abide by the legal requirements associated with these rights.

\section{Takedown policy}

If you believe that this document breaches copyright please refer to the University of Manchester's Takedown Procedures [http://man.ac.uk/04Y6Bo] or contact uml.scholarlycommunications@manchester.ac.uk providing relevant details, so we can investigate your claim.

\section{OPEN ACCESS}




\title{
Embracing Advanced Digital Services in the Charity and Voluntary Sector: A Response to Covid-19
}

\author{
A. Raki*, I. N. Chowdhury, M. Nieroda \& J. Zolkiewski \\ Alliance Manchester Business School, The University of Manchester, United Kingdom \\ amir.raki@manchester.ac.uk \\ ilma.chowdhury@manchester.ac.uk \\ marzena.nieroda@manchester.ac.uk \\ judy.zolkiewski@manchester.ac.uk
}

Keywords: Advanced Services, Charity and Voluntary Sector, Digitalisation, Transformative Service Research, Wellbeing

\begin{abstract}
Charity and voluntary services require significant human-to-human interactions alongside integrative offerings inclusive of core and complementary services to yield value and improve the wellbeing of their often vulnerable service users. The COVID-induced digitalisation of such services can pose a challenge to the productivity and resilience of the charity and voluntary sector as the extent to which human interactions and holistic offerings are replicable in digital services can be limited and can diminish the wellbeing outcomes of offerings. This research employs a transformative service research lens to study the digital transformation of charity and voluntary services in accordance with the concept of advanced services to generate insight into the capabilities necessary at the organisational level and quality of interactions required at the interactional level that can enable the sector to offer digitally enhanced advanced services. By identifying the antecedents of advanced digital service in the charity and voluntary sector, this research provides new opportunities to the sector to capitalise on the advantages of digitalisation whilst responding to their service users' multiplex needs which in turn improves the sector's resilience and productivity.
\end{abstract}

\section{Introduction}

Charity and Voluntary Services (CVSs) are inherently transformative as their focus is on the delivery of the wellbeing outcomes for service users and not merely the delivery of services [1]. This transformative characteristic is often operationalised through the combination of a core service (e.g., education, skills training, money matters, etc.) with complementary peripheral services (e.g., emotional support, social capital, confidence building, etc.). Although servitization has mainly focussed on manufacturing, recently it has been demonstrated that the transformation process that servitization engenders can be applied more broadly in any firm that is transforming [2]. Adopting this stance, CVSs could be considered advanced services as they bundle together various resources in a holistic offering, specific to individual's multiplex needs and wants, which supports service users/consumers and is critical to their wellbeing [3,4]. On that account, being personcentred, holistic and value-centric (i.e., wellbeing) are distinguishing characteristics of advanced CVSs against the base or intermediate services that are just focused on service processes and/or delivery. 
The outbreak of COVID-19 has led to large-scale service disruptions and significant changes in the ways through which people access and utilise services. In the charity and voluntary sector, the pandemic has had a severe impact on the instrumental, social, and emotional needs of their often-vulnerable service users. Simultaneously, the resilience and productivity of the sector to adapt to new ways of service delivery, particularly digitalisation of their services, whilst maintaining service continuity and efficacy was tested to the extreme. In the digital transformation of CVSs, the main challenge was how to maintain the advanced attributes of the service because the extent to which these characteristics can be replicated in digital services appears limited.

Boosting the sector's digital capabilities is increasingly necessary to form the foundation for growing the sustainability and resilience of the sector and addressing the digital divide to ensure an inclusive digital economy. Thus, the specific objective of this study was to identify the antecedents of digitally enhanced advanced service in the charity and voluntary sector at organisational (meso) and interactional (micro) level and investigate potential implications for the resilience and productivity of the sector.

\section{Theoretical Background}

The ability to maintain the service continuity and operational function at the desired level under the influence of the change and disturbance is a key determinant of an organisation's resilience [5]. Similarly, it is associated with the sector's productivity that is the capacity to create more value for the same amounts of input to improve service users' perception of value and quality [6]. Therefore, to sustain the resilience and productivity of the charity and voluntary sector following its digital transformation, it is imperative to explore service users' experiences of digital CVSs particularly, regarding the advanced characteristics of the service (i.e., person-centred integrative and value-centred).

Moreover, the focus of advanced services on the new ways of delivering value and new relationships assigns specific roles to the people who deliver these services and service efficacy is contingent on how these people interact to offer a service that supports service users/customers [7]. This requires an integrated network of resources, beyond the focal service, interacting together to generate capabilities required to deliver advanced services [8]. In the same vein, in the charity and voluntary sector, transformation occurs through the social process of interactions with others which requires not only the presence of and direct interactions with services that are grounded in service users' needs and wants but also indirect engagement and meaningful interactions with others for integration of resources and value creation.

Accordingly, this research explores the experiences of service users and service providers from the COVID-induced digital CVSs to generate insight into capabilities necessary to deliver advanced digital CVSs and the characteristics of interactions required to support their service users.

\section{Methodology}

To answer the research questions, an exploratory study was undertaken on an education service for refugee learners, provided by a charity, which had been transitioned online since the beginning of the pandemic. Data were collected by conducting 25 interviews with frontline service employees, volunteers and service users and two focus groups. Moreover, a member of the research team has participated in various online sessions to observe service 
interactions and collect fieldnotes. The collected data were analysed by employing a thematic analysis approach to discover the main themes that indicate organisational capabilities and quality of interactions required to deliver advanced digital CVSs.

\section{Findings and Discussion}

This research responds to the call to study the adoption of servitization and advanced services in non-manufacturing contexts. Exploring the capabilities required to deliver advanced digital CVSs, the identified factors are: 1) flexibility not only to adapt to the changing environment but also to the changing consumer needs, 2) agility in creating changes that respond to consumers' changing needs, 3) effectiveness in meeting service users' multiplex needs and expectations, 4) the ability to bricolage and create value with what is at hand rather than seeking extra resources, and 5) maintaining strong charitable values that manifests in the practitioners' practices and informs digital transitioning.

Moreover, unravelling the missing elements of the human touch in digital CVSs, five main themes were revealed: 1) lack of opportunities to initiate and maintain constructive and effective dialogue, 2) lack of warmth, as often experienced in face-to-face interaction, 3) lack of sensory cues such as eye contact, non-verbal cues and body language, 4) lack of attentiveness from service employees which prevents participants' feelings of being recognised and significant, and 5) lack of opportunities to offer personalised services that meet individuals' needs beyond the core service.

This study enhances our understanding of advanced services in the charity and voluntary sector. The research findings suggest that to create digitally enhanced advanced offerings in the sector, the quality of interactions, by shaping the flow of social resources, is largely responsible for determining service users' perception of value. Furthermore, this research elucidates organisational capabilities that need to be nurtured in the charity and voluntary sector in order to embrace digitally enhanced advanced services.

\section{Managerial Implications}

By discovering the antecedents of advanced digital CVSs and characteristics of service interaction in a digitally enhanced advanced service setting, this study offers new opportunities to the sector to capitalise on the advantages of digitalisation whilst responding to their service users' needs which improves the resilience and productivity of the sector.

Furthermore, as the main objective of the charity and voluntary sector is to improve the quality of life for vulnerable populations, this research's outcomes generate insight into how to augment human touch in CVSs to uphold consumer wellbeing. Finally, the results of this study shed light on the scope for the sector to narrow the digital divide by offering meaningful and beneficial digital services to vulnerable consumers and contribute to an inclusive digital economy.

\section{Acknowledgements}

This research was supported by a DEAS Network Plus Charity/Voluntary Projects research grant.

\section{References}

[1] Anderson, L. and Ostrom, A. L., "Transformative Service Research: Advancing Our Knowledge About Service and Well-Being," Journal of Service Research, Editorial vol. 18, 
no. 3, pp. 243-249, Aug 2015.

[2] Zolkiewski, J., Burton, J., Ausaf, G., et al., "Understanding the challenges of digital servitization in healthcare," Submitted to the Spring Servitization Conference 2021.

[3] Baines, T., Bigdeli, A. Z., Bustinza, O. F., et al., "Servitization: revisiting the state-ofthe-art and research priorities," International Journal of Operations \& Production Management, 2017.

[4] Mathieu, V., "Product services: from a service supporting the product to a service supporting the client," Journal of Business \& Industrial Marketing, 2001.

[5] Rapaccini, M., Saccani, N., Kowalkowski, C., et al., "Navigating disruptive crises through service-led growth: The impact of COVID-19 on Italian manufacturing firms," Industrial Marketing Management, vol. 88, pp. 225-237, 2020.

[6] Grönroos, C. and Ojasalo, K., "Service productivity: Towards a conceptualization of the transformation of inputs into economic results in services," Journal of Business Research, vol. 57, no. 4, pp. 414-423, 2004.

[7] Baines, T., Lightfoot, H., Smart, P., et al., "Servitization of manufacture: Exploring the deployment and skills of people critical to the delivery of advanced services," Journal of Manufacturing Technology Management, 2013.

[8] Story, V. M., Raddats, C., Burton, J., et al., "Capabilities for advanced services: A multiactor perspective," Industrial Marketing Management, vol. 60, pp. 54-68, 2017. 